doi:10.1017/\$1041610219000164

\section{Analysis of the relationship between the autonomy of Turkish elderly people and their happiness and anxiety-depression status: a cross-sectional study}

Compared to other age groups, the number of elderly in the population is increasing rapidly in Turkey. According to the findings of the Turkish Statistical Institute, people over the age of 65 constituted $8.2 \%$ of the total population in 2016 . This ratio is expected to increase to $10.2 \%$ in 2023 , $20.8 \%$ in 2050 , and $27.7 \%$ in 2075 (TSI, 2019). Today, health policies in Turkey and abroad are attempting to maintain the autonomy of the elderly and their integration into society. Due to the relationship between physical and functional capacity decreases their autonomy (Faustino et al. 2014). This can lead to such problems as social isolation, unhappiness, and depression (Azevedo et al. 2014, Bhamani et al. 2014).

The aim of this cross-sectional study is to analyze the relationship between the autonomy of people over the age of 65 who live at home and their happiness and anxiety-depression status. This study was conducted between January and April 2014, in Ankara, Turkey with 210 participants. The Functional Autonomy Measurement System, the Oxford Happiness Questionnaire Short Form (OHQ-SF), and the Hospital Anxiety and Depression Scale were used for data collection. Ethical and administrative permissions were granted by the ethical committee of the institution (1491-29-14/1648-4246).

Most of the participants $(71.9 \%)$ are female, with an average age of $72 \pm 6.82$. The participants $(64.3 \%)$ stated that they engaged in social activities, and met mostly with friends. The other participants $(36.7 \%)$ stated that their personality characteristics, experiences, and families influenced their life decisions.

Only $10 \%$ of the participants of this research were autonomous. Autonomy levels of the participants were related to their age, marital status, education, social activity engagement, place of residence, and doing exercise $(p<0.05)$. As age increased so did their dependence level. Participants who did not do any exercise, did not live in their own house, and did not engage in social activities, were more dependent and less autonomous $(\mathrm{p}<0.05)$. Participants who did not engage in social activities $(p=0.002)$, did not exercise $(p<0.001)$, scored statistically significant less on the OHQ-SF.

Linear regression analysis of all the factors shows that absence of social activities, not living in one's own house, and aging are related to autonomy $(p<0.05)$. The study found no relationship between autonomy levels and anxiety and that decreasing autonomy levels was associated with unhappiness and higher depression among the elderly.

The results of this study show that aging is associated with lower autonomy for elderly people. Decreasing autonomy levels was associated with unhappiness and higher depression. In order to increase autonomy among the elderly, daily and social activities should be supported. It is stated that a larger number of leisure activities and a larger number of close friends were significantly related to better cognitive performance (Ihle et al., 2018). During the planning of health care for elders, and to maintain their physical, mental, emotional, and social well-being should be evaluated from an integrated perspective.

\section{Author contributions}

ST, HA, GK and EI and participated in the initial design of th estudy. SG collected data. ST, HA and GK performed the statistical analysis. ST, HA, GK and EI wrote draft manuscript. All authors read and approved the final manuscript.

\section{References}

Azevedo, L.M., Oliveira, K.M., Nunes, V.M. and Alchieri, J.C. (2014). Losses of functional capacity in elderly institutionalized in the city of Natal/Rio Grande do Norte. Fournal of Research: Fundamental Care Online, 6, 485-492.

Bhamani, M.A., Khan, M.M., Karim, M.S. and Mir, M.U. (2014). Depression and its association with functional status and physical activity in the elderly in Karachi, Pakistan. Asian Fournal of Psychiatry, 14, 46-51.

Faustino, A.M., Gandolfi, L. and Moura, L.B. (2014). Functional capability and violence situations against the elderly. Acta Paulista de Enferm, 27, 392-398.

Ihle, A., Oris, M., Baeriswyl, M. and Kliegel, M. (2018). The relation of close friends to cognitive performance in old age: the mediating role of leisure activities. International Psychogeriatrics, 30,1753-1758. doi: 10.1017/ S1041610218000789. 
Turkish Statistical Institute (TSI). (2019). Elderly statistics 2016. http://www.tuik.gov.tr/PdfGetir.do? id=24644; last accessed 10 January 2019.

Sevinc Tastan, ${ }^{1}$ Hatice Ayhan, ${ }^{2}$ Gulsah Kose, ${ }^{3}$ EMINE IYIGUN $^{2}$ AND SERAy GoKCUL ${ }^{4}$

${ }^{1}$ Eastern Mediterranean University, Health Sciences Faculty, Nursing Department, Via Mersin 10, Famagusta, North Cyprus, Turkey

${ }^{2}$ University of Health Sciences, Gulhane Faculty of Nursing, Ankara, Turkey
${ }^{3}$ Mugla S1tk1 Kocman University, Faculty of Health Science, Department of Nursing, Kotekli, Mugla, Turkey

${ }^{4}$ Izmir Katip Celebi University Ataturk Education and Research Hospital, Izmir, Turkey

Correspondence should be addressed to: Sevinc Tastan, Eastern Mediterranean University, Health Sciences Faculty, Nursing Department, Via Mersin 10,

Famagusta, North Cyprus, Turkey. Email: sytastan@ gmail.com. Phone: +90 5488785465 